\title{
MOVEMENT DISORDERS IN 28 HIV-INFECTED PATIENTS
}

\author{
James Pitágoras de Mattos' , Ana Lúcia Zuma de Rosso², \\ Rosalie Branco Corrêa ${ }^{3}$, Sérgio A.P. Novis ${ }^{4}$
}

ABSTRACT - From 1986 to 1999, 2460 HIV-positive inpatients were seen in our Hospital. Neurological abnormalities were detected in $1053(42.8 \%)$ patients. In this group, 28 (2.7\%) had involuntary movements, 14 $(50 \%)$ with secondary parkinsonism, six (21.4\%) with hemichorea/hemiballismus, four (14.2\%) with myoclonus, two $(7.2 \%)$ with painful legs and moving toes, one $(3.6 \%)$ with hemidystonia and one $(3.6 \%)$ with Holmes' tremor. The HIV itself (12 patients), toxoplasmosis of the midbrain (1) and metoclopramide-related symptoms (1) were the most probable causes for the parkinsonism. All patients with hemichorea/hemiballismus were men and in all of them toxoplasmosis of the basal ganglia, mostly on the right side, was the cause of the involuntary movements. Generalized myoclonus was seen in two patients and they were due to toxoplasmosis and HIV-encephalopathy respectively; two others presented with spinal myoclonus. The two patients with painful legs and moving toes had an axonal neuropathy. The patient with hemidystonia suffered from toxoplasmosis in the basal ganglia and the patient with Holmes' tremor had co-infection with tuberculosis and toxoplasmosis affecting the midbrain and cerebellum. We conclude that HIV-infected patients can present almost any movement disorder. They can be related to opportunistic infections, medications, mass lesions and possibly to a direct or indirect effect of the HIV itself.

KEY WORDS: AIDS, HIV, movement disorders, parkinsonism.

\begin{abstract}
Distúrbios do movimento em 28 pacientes infectados pelo HIV
RESUMO - De 1986 a 1999, 2460 pacientes HIV-positivos internados foram avaliados em nosso Hospital. Alterações neurológicas foram encontradas em 1053 (42,8\%). Neste grupo, 28 (2,7\%) exibiam movimentos involuntários, $14(50 \%)$ com parkinsonismo secundário, seis $(21,4 \%)$ com hemicoréia/hemiballismo, quatro $(14,2 \%)$ com mioclonias, dois $(7,2 \%)$ com painful legs and moving toes, um $(3,6 \%)$ com hemidistonia e um (3,6\%) com tremor de Holmes. No grupo com parkinsonismo, 12 eram, provavelmente, secundários ao HIV; um à toxoplasmose mesencefálica e outro desencadeado pela metoclopramida. Todos com hemicoréia/ hemiballismo eram homens e estavam relacionados com toxoplasmose nos gânglios da base. Nos quatro pacientes com mioclonia, em dois era generalizada, relacionada, em um, com toxoplasmose e, em outro, com a encefalopatia pelo HIV; nos outros dois era de origem medular. Nos dois pacientes com painful legs and moving toes, ficou demonstrada a neuropatia axonal pela biópsia do nervo periférico. Toxoplasmose da gânglia basal estava relacionada com hemidistonia contralateral. No paciente com tremor de Holmes havia lesões no mesencéfalo e no cerebelo, secundárias à co-infecção pelo bacilo da tuberculose e pelo Toxoplasma gondii. Concluímos que diversos distúrbios do movimento podem ocorrer em pacientes infectados pelo HIV. Costumam estar relacionados às infecções oportunísticas, ao uso de certos medicamentos, às lesões com efeito de massa e, possivelmente, à ação direta ou indireta do HIV.
\end{abstract}

PALAVRAS-CHAVE: SIDA, HIV, distúrbios do movimento, parkinsonismo.

Berger et al.(1984) ${ }^{1}$ were the first to report involuntary movements in AIDS on the literature. This was followed by the descriptions of Navia et al. ${ }^{2}$ (1986) and Nath et al. ${ }^{3}$ (1987). The first Brazilian report came out in 1992 from Mattos et al. ${ }^{4}$. Since then, a wide variety of movement disorders have been described, including: parkinsonism, hemichorea/hemiballismus, myoclonus, dystonia, tremor, and painful legs and moving toes ${ }^{5-13}$. It is known that in AIDS patients, the damage of central nervous system (CNS) can be related to opportunistic infections, neoplasms and possibly to an indirect or direct effect of the HIV itself ${ }^{5}$. The main opportunistic infections are toxoplasmosis, cryptococcosis, cytomegalovirus, tuberculosis and progressive multifocal leukoencephalopathy ${ }^{14}$. Our main goal is to show the experience with sev-

\footnotetext{
Department of Neurology, Clementino Fraga Filho University Hospital, Federal University of Rio de Janeiro, Rio de Janeiro RJ, Brazil: ${ }^{1} \mathrm{MD}$, $\mathrm{PhD}$, Associate Professor, Movement Disorders Sector; ${ }^{2} \mathrm{MD}$, PhD, Neurologist, Movement Disorders Sector; ${ }^{3} \mathrm{MD}, \mathrm{MsC}$, Neurologist, Neuro-infections Sector; ${ }^{4} \mathrm{MD}, \mathrm{PhD}$, Full Professor of Neurology.
}

Received 27 October 2001, received in final form 31 January 2002. Accepted 8 February 2002. 
eral movements disorders observed in HIV-positive inpatients in a period from 1986 to 1999.

\section{METHOD}

In 14 years (1986-1999) 2460 HIV-positive inpatients were seen in our hospital; 1053 (42.8\%) presented at least one neurological manifestation. Of them, 28 (2.7\%) had involuntary movements and were studied prospectively. With the exception of three all patients were men. The mean age at the onset of the movement disorder was 35.6 years (ranging from 25 to 63 years). According to high-risk categories 12 were homosexual, eight bisexual, five intravenous drug users (IDU), and one had a history of blood transfusion. In four patients no risk factor was identified. Two patients belonged to more than one category. All patients were on the AIDS stage according to Center of Disease Control (CDC) / World Health Organization (WHO) classification system ${ }^{15}$.

\section{RESULTS}

The clinical features of our 28 HIV patients with movement disorders are depicted in the Table. The figure illustratres neuroimage findings.

Parkinsonism - It was observed in 14 patients (50\%). Eleven were males and three females. Twelve were Caucasian and two African-Brazilian. The mean age at the onset of the parkinsonian symptoms was 37.2 years (range from 25 to 63). According to the high-risk category, five were homosexual, three bisexual, two IDU and one had a blood transfusion. Four patients did not show any identifiable risk. Tremor was seen in eight (57.2\%) as the initial symptom. At the first examination patients had a mean score in the Hoehn \& Yahr scale of 2.5 (range from 1 to 5). All patients underwent CT scans. Seven (50\%) showed ex-vacuum hydrocephaly due to corticalsubcortical atrophy. One patient had a hypodense area with mass effect suggestive of toxoplasmosis of the right basal ganglia. One had an enhancing lesion in the midbrain at the T1 weighted MRI, which

Table. Clinical features of 28 HIV-infected inpatients.

\begin{tabular}{lcc}
\hline Movement disorders & No. & $\%$ \\
\hline Parkinsonism & 14 & 50.0 \\
Hemichorea/hemiballismus & 6 & 21.4 \\
Myoclonus & 4 & 14.2 \\
Painful legs and moving toes & 2 & 7.2 \\
Hemidystonia & 1 & 3.6 \\
Holmes' tremor & 1 & 3.6 \\
\hline
\end{tabular}

was correlated clinically with a homolateral ophthalmoplegia and contralateral hemiparkinsonism (Benedikt syndrome). The parkinsonism was probably secondary to HIV in 12 , to metoclopramide in one and to neurotoxoplasmosis in another one. The mean time from the HIV diagnostic to the onset of the symptoms was five months. Only five out of nine patients that used levodopa had mild improvement. In eight patients the mean time from the onset of parkinsonism and death was five months.

Hemichorea/Hemiballismus - This abnormal movement was present in six (21.4\%) patients and all were male. The neuroimaging revealed enhancing ring lesions in the basal ganglia or in the frontal lobes suggestive of toxoplasmosis. Intracranial hypertension with mass lesions was present in two patients. In five (83\%) the movement was on the left side. The mean age of onset of the choreic movements was 32.5 years (range from 27 to 40). The high-risk behavior was three bisexual, two homosexual and two IDU. The mean time between the HIV diagnostic and the hemichoreia/hemiballismus was 28 months (range from 0 to 60 months). It must be emphasized that in two (33\%) patients the hemichorea/hemiballismus was the first clinical manifestation of AIDS.

Myoclonus - Myoclonus was observed in four $(14.2 \%)$ patients, generalized in two and restricted to the lower limbs (spinal myoclonus) in two. All patients were males and the mean age at the onset of the abnormal movement was 30.2 years (range from 26 to 40 years). The high-risk behavior was homosexualism in three and IDU in one. In the first patient the abnormal movement was related to neurotoxoplasmosis, and in the second probably to HIV encephalopathy. The third patient developed radiculomyelopathy most likely due to Mycobacterium tuberculosis. In the fourth patient the myoclonus was probably due to dorsal herpes zoster. One patient with generalized myoclonus had cortical-subcortical atrophy in the CT scan. In another one with spinal myoclonus the CSF examination was positive for HIV, CMV, Mycobacterium tuberculosis and herpes simplex. The myoclonus was recorded by electromyography in those with spinal myoclonus.

Painful legs and moving toes (PLMT) - Two patients had bilateral and asymmetrical involuntary movements in the first and second toes. A mixture of flexion, extension, abduction and adduction of toes in an almost continuous fashion characterized them. The movements were exacerbated by the supine 
position, disappearing for some time with voluntary movement of the lower limbs. Both patients were homosexual males, with a mean age of 44.5 years (38 and 51 years). The mean duration between the HIV diagnostic and the involuntary movements was 4 years ( 3 and 5 years). These individuals also had a concomitant peripheral neuropathy mainly affecting the lower limbs. In one of these the electromyography established the diagnosis of peripheral neuropathy; the CSF examination showed mild mononuclear pleocytosis and the nerve biopsy were consistent with HIV-related axonal neuropathy.

Hemidystonia - A 28 year-old bisexual male patient presented with hemidystonia on the right side due to toxoplasmosis of the contralateral basal ganglia. It started three months after the onset of the HIV encephalopathy and 16 months after the diagnosis of the HIV infection. The treatment with sulfadiazine and pyrimethamine improved the radiological lesion but did not change the movement disorder.

Holmes' tremor - Two years after the HIV diagnosis a 34 year-old homosexual man presented with signs and symptoms of intracranial hypertension. A lesion in the left midbrain and another in the left cerebellar hemisphere were seen in the CT scan. A biopsy of the cerebellar mass lesion disclosed tuberculosis. This material was inoculated into a rabbit brain where toxoplasmosis abscess developed suggesting a coinfection. During the treatment a postural, coarse and high amplitude tremor appeared in the left upper limb indicating Holmes' tremor. The midbrain and cerebellar lesions, as well as the postural tremor and the intracranial hypertension disappeared with the specific treatment for tuberculosis and toxoplasmosis.

\section{DISCUSSION}

Since 1986 the Clementino Fraga Filho University Hospital - the Federal University of Rio de Janeiro has been a reference center for HIV-positive patients. Since then the Department of Neurology has been following patients with neurological manifestations. In this group 28 (2.7\%) have abnormal movement. We will now discuss the 28 HIV inpatients with movement disorders.

Parkinsonism - In our study, parkinsonism was the most frequent (50\%) movement disorder. Of the 14 parkinsonian patients we found a large prevalence of males, a fact that is not seen in idiopathic Parkinson's disease. ${ }^{15}$ However, like the literature, Caucasians were more frequent in our series ${ }^{15}$. In terms of age it is im- portant to note the onset before the 40 's. This should be seen as an important clue to the diagnosis of secondary parkinsonism in young adults.

Half of our parkinsonian patients at that time were homo or bisexual males, however, the behavior of the HIV infection has changed over the last few years and the risk factors are no longer applied. Tremor was the most frequent symptom at the onset of parkinsonism in our study, as seen in idiopathic Parkinson's disease ${ }^{15}$.

All of our patients had a cerebral image scans. They showed hydrocephalus with cortical-subcortical atrophy in half, fine calcification in the basal ganglia in one, hypodense mass lesion in the striatum in one and hyperintensity lesion in the midbrain in another patient. Both images were suggestive of toxoplasmosis. We speculate that the brain atrophy in these patients was related to the HIV encephalopathy. The calcifications could probably be secondary to the HIV encephalopathy or be casual findings as in non-HIV patients. Although the mass lesion on the basal ganglia was suggestive of toxoplasmosis, it had no clinical correlation with the parkinsonian symptoms because it remained present after the successful treatment for toxoplasmosis. However, in the patient with the Benedikt syndrome probably due to toxoplasmosis in the contralateral midbrain, there was a definitely clinical correlation since we observed improvement on the ophthalmoplegia and parkinsonian signs and symptoms after treatment.

We could only established a clear cause for the parkinsonism in two patients: one due to high doses of metoclopramide and another one due to toxoplasmosis of the midbrain. In the remaining 12 patients there was no clear association with any infectious, neoplastic, vascular or drug-related cause. Subsequently we hypothesize that the signs and symptoms in these patients were related to the HIV itself.

The mean time between the HIV diagnosis and the onset of the parkinsonism, and between parkinsonism and death were similar (5 months). These observations show the severity and the poor prognosis of the HIV related parkinsonism. In the last few years we have been observing the decreasing of cases not only of parkinsonism but also of others involuntary movements in HIV positive patients. This observation may be related to the introduction of highly active antiretroviral therapy (HAART). This has resulted in the decline in the AIDS' death rate and in the incidence rates for various opportunistic infections, including cytomegalovirus disease, atypical mycobac- 


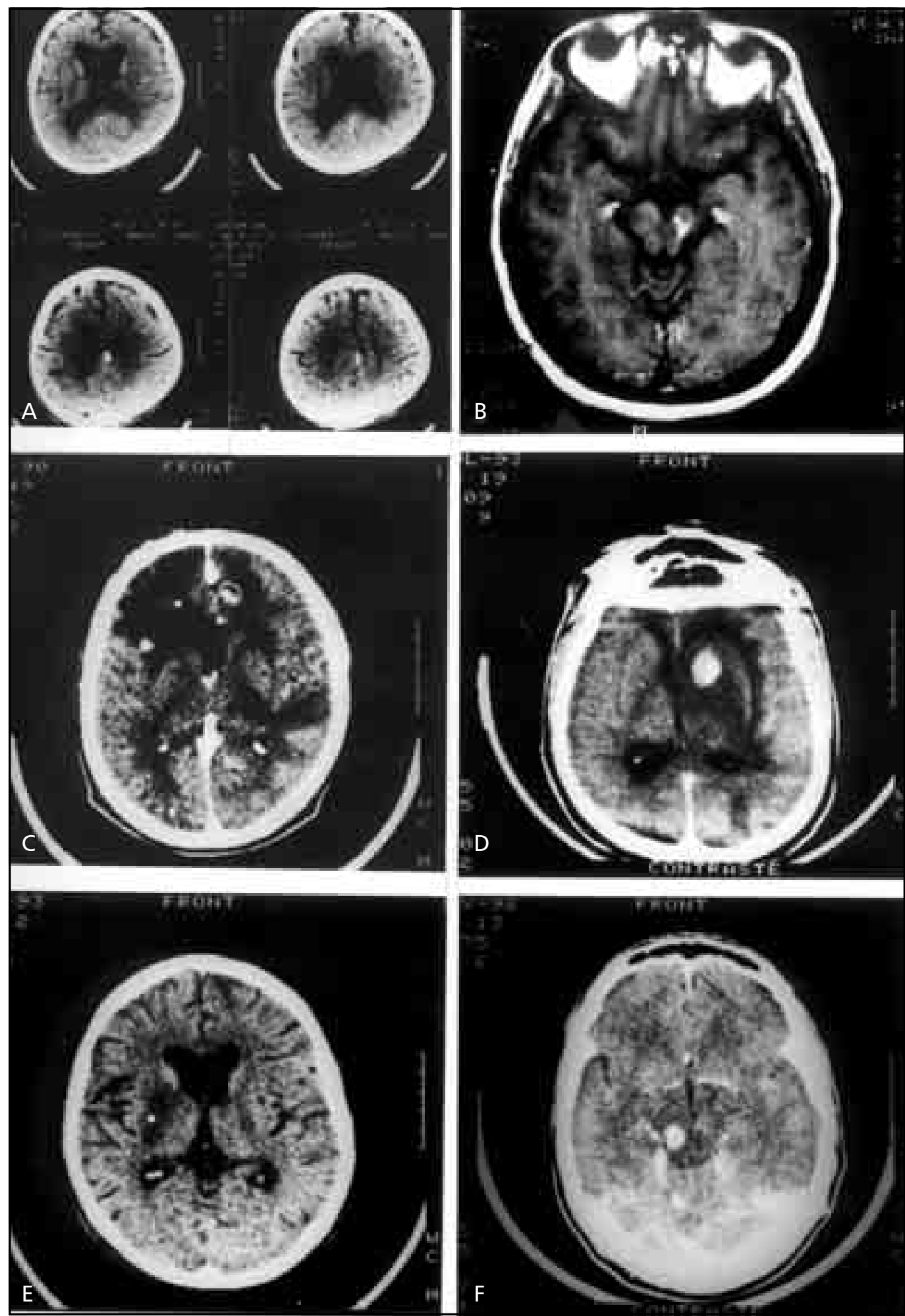

Figure. A. Unenhanced CT scan from a parkinsonian patient showing ex-vacuum hydrocephalus secondary to subcortical-cortical atrophy. B. MRI illustrating a T1-weighted high signal intensity in the left midbrain due to toxoplasmosis that correlated with contralateral hemiparkinsonism. C. Enhanced CT scan demonstrating extensive mass lesions in both frontal lobes in a patient with hemichorea/hemiballism. D. Enhanced CT scan showing hyperdense nodular lesion in the head of the right caudate nucleus in a patient with hemichorea/ hemiballism. E. Unenhanced CT scan illustrating hypodense lesion in the left striatum suggestive of toxoplasmosis that correlated with contralateral hemidystonia. F. Enhanced CT scan demonstrating two nodular lesions - left midbrain and cerebellar hemisphere - due to co-infection (tuberculosis and toxoplasmosis) in a patient with Holmes' tremor. 
terial infection, and toxoplasmosis. Taken together these facts will result in a decrease of neurological complications of AIDS.

Hemichorea/Hemiballism - Although some studies had showed that hemichorea/hemiballism $(\mathrm{H} / \mathrm{H})$ was the most frequent involuntary movement in HIV positive patients ${ }^{14}$, in our series it was the second most common. $\mathrm{H} / \mathrm{H}$ affected six (21.4\%) patients. Curiously all were male and in all of them $\mathrm{H} / \mathrm{H}$ was secondary to toxoplasmosis of the CNS. The acute onset of $\mathrm{H} / \mathrm{H}$ in young patients, as seen in our series, should always raise the suspicion of HIV and toxoplasmosis of the CNS. In contrast, in older patients $\mathrm{H} / \mathrm{H}$ is most frequently due to vascular lesions.

$\mathrm{H} / \mathrm{H}$ may be the very first symptom of AIDS, as seen in two of our patients. This is corroborated by the time between the HIV diagnosis and the onset of the involuntary movements, which ranged from 0 to five years in our series. In five (83\%) H/H occurred on the left side and in only one (17\%) on the right. This fact confirms a wise and old observation from Charcot that $70 \%$ of $\mathrm{H} / \mathrm{H}$ were on the left side. The neuroimaging in all patients showed the usual multiple lesions seen in toxoplasmosis of the CNS located at the frontal lobes and striatum.

Myoclonus - In the same way of what we observed in our patients with $\mathrm{H} / \mathrm{H}$, all with myoclonus were also male and the onset of the involuntary movements were in the fourth decade. The myoclonus was generalized (cortical) in two and localized (spinal) in two. Three patients were homosexual and one was an IDU. In three individuals the cause of the myoclonus was opportunistic infection (toxoplasmosis, tuberculosis and herpes zoster) and in one the absence of any infection suggested that the involuntary movement was probably secondary to HIV encephalopathy. In only one patient the myoclonus was the first manifestation of the HIV infection.

Painful legs and moving toes - Two patients with HIV-related painful legs and moving toes (PLMT) were described in 1999 by one of the authors (JPM) and were the first such patients reported in the literature $^{13}$. The first was a 38-years-old homosexual man in the late stage of AIDS. He had been treated for cryptococcus meningitis, pulmonary tuberculosis and cytomegalovirus. He presented with HIV encephalopathy and an extremely painful peripheral neuropa- thy initiated three years after seroconversion. Subsequently he presented with PLMT. The second, a 51-years-old homosexual man, had similar involuntary movement five years after the seroconversion. He also presented with a painful, drug-resistant (amitriptiline, baclofen, carbamazepine, gabapentine), peripheral neuropathy.

We should emphasize that our patients had similar clinical features to those with non-AIDS PLMT and that the onset of very painful peripheral neuropathy with PLMT in young patients could be related with HIV infection.

Hemidystonia - The hemidystonia in our patient was secondary to a hypodensity mass lesion in the contralateral basal ganglia that was suggestive of toxoplasmosis. After treatment for toxoplasmosis encephalitis there was improvement of the lesions but not of the involuntary movement.

Holmes' tremor - In our patient with Holmes' tremor the two lesions seen at CT scans (midbrain and cerebellar) were secondary to co-infection - tuberculosis and toxoplasmosis. This is corroborated by the regression of all signs and symptoms after therapy to both infections.

\section{CONCLUSIONS}

In our 28 HIV positive inpatients with involuntary movement, 14 (50\%) presented with parkinsonism, six (21.4\%) with hemichorea/hemiballism, four (14.2\%) with myoclonus, two (7.2\%) with PLMT, one (3.6\%) with hemidystonia and one $(3.6 \%)$ with Holmes' tremor.

Parkinsonism secondary to AIDS should always be thought in young adult males with rapid onset and deterioration of the parkinsonian symptoms. In the majority of these patients $(12 / 14)$ there was no clear association with infectious, neoplastic or drugrelated cause. We speculate that the clinical features of these patients were related to the HIV itself.

Toxoplasma encephalitis should be considered in young adults with hemichorea/hemiballism.

The myoclonus in HIV positive patients had no specific features and could be either generalized or focal. It could be secondary to opportunistic infections or to the HIV itself.

PLMT secondary to AIDS must be in the differential diagnosis of others PLMT, in particular in young adults with painful axonal neuropathy. 
We conclude that the movement disorders observed in AIDS patients may be related to opportunistic infections, to certain drugs and probably to the direct or indirect effect of the HIV.

Acknowledgements - We are indebt to Prof. Abelardo Araújo for his assistance in the reviewing the manuscript.

\section{REFERENCES}

1. Berger JR, Moskowitz L, Fischl M, Kelley RE. The neurologic complications of AIDS: frequently the initial manifestation. Neurology 1984; 34(Suppl):134-135.

2. Navia BA, Jordan BD, Price RW. The AIDS dementia complex: I. Clinical features. Ann Neurol 1986;19:517-524.

3. Nath A, Jankovic J, Pettigrew LC. Movement disorders and AIDS. Neurology 1987;37:37-41.

4. Mattos JP, Rosso ALZ, Correa RB, Novis S. Involuntary movements and AIDS: report of seven cases and review of the literature. Arq Neuropsiquiatr 1993;51:491-497.

5. Carrazana E, Rossitch E Jr, Samuels MA. Parkinsonian symptoms in a patient with AIDS and cerebral toxoplasmosis. J Neurol Neurosurg Psychiatry. 1989;52:1445-1446.
6. Abbruzzese G, Rizzo F, Dall'agata D, Morandi N, Favale E. Generalized dystonia with bilateral striatal computerized tomography lucencies in a patient with human immunodeficiency virus infection. Eur Neurol 1990;30:271-273.

7. Tolge CF, Factor SA. Focal dystonia secondary to cerebral toxoplasmosis in a patient with acquired immunodeficiency syndrome. Mov Disord 1991;6:69-72.

8. Nath A, Hobson DE, Russell, A. Movement disorders with cerebral toxoplasmosis and AIDS. Mov Disord 1993;8:107-112.

9. Factor SA, Podskalny GD, Barron KD. Persistent neuroleptic-induced rigidity and dystonia in AIDS dementia complex: a clinico-pathological case report J Neurol Sci 1994,127:114-120.

10. Lubetzki $\mathrm{C}$, Vidailhet $\mathrm{M}$, Jedynak $\mathrm{CP}$, et al. Myoclonies propriospinales chez un patient séropositif pour le virus de l'immunodéficience humaine. Rev Neurol 1994:150:70-72.

11. Gallo BV, Shulman LM, Weiner WJ, Petito CK, Berger JR. HIV encephalitis presenting with severe generalized chorea. Neurology 1996, 46:1163-1165.

12. Maher J, Choudhri S, Halliday W, Powers C, Nath A. AIDS dementia complex with generalized myoclonus. Mov Disord 1997;12:593-597.

13. Mattos JP, Py MO, André C. Painful legs and moving toes associated with neuropathy in HIV-infected patients. Mov Disord 1999;14:10531054.

14. Cardoso F. Infectious and transmissible movement disorders. In Jankovic J, Tolosa E (eds). Parkinson's disease and movement disorders. 3.Ed. Baltimore: Williams \& Wilkins, 1998:945-965

15. Rosso ALZ. Contribuição para o estudo do parkinsonismo secundário à síndrome de imunodeficiência adquirida. Tese (Doutorado). Universidade Federal do Rio de Janeiro. Rio de Janeiro, 1998. 